\title{
RECUSA AO ATO NA ADOLESCÊNCIA: UMA "REAÇÃO SUBJETIVA NEGATIVA"?
}

Marta Rezende Cardoso*

Psicanalista; doutora em Psicopatologia Fundamental e Psicanálise, Universidade de Paris Diderot, Paris 7 (França); professora associada do Instituto de Psicologia da UFRJ (Programa de Pós-Graduação em Teoria Psicanalítica); membro da Associação Universitária de Pesquisa em Psicopatologia Fundamental. Pesquisadora do CNPq (bolsa de produtividade em pesquisa).

\begin{abstract}
RESUMO: Estuda-se a questão da violência psíquica na adolescência, em certas patologias do ato, em particular as situações clínicas marcadas pelo negativo desse registro: a recusa radical no plano do agir. Isto se vê na morosidade no ingresso na vida adulta, na conduta de retraimento de certos adolescentes que parecem "resistir" à superação da condição adolescente. Apesar da aparente contradição, situa-se o "recurso ao ato" e a "recusa ao agir" no campo das patologias do ato: o ego atua uma defesa extrema em cuja base insiste uma dimensão traumática, de passividade ante a pulsão.
\end{abstract}

Palavras-chave: adolescência, violência, passividade, recurso ao ato, recusa a agir.

ABSTRACT: Refusal to acting in adolescence: a "negative subjective reaction?". We study the issue of psychological violence in adolescence, in certain pathologies of the act, particularly the clinical situations marked by the negative of that register: the radical refusal to acting. This is manifested in the delay in entering adulthood, in the withdrawal behavior of certain adolescents who seem to "resist" overcoming the adolescent condition. In spite of the apparent contradiction, we place the "resource to the act" and the "refusal to acting" in the clinical field of the pathologies of the act: the ego acts in an extreme defense, which in its basis has the insistence of a traumatic dimension of passiveness in front of the drive.

Keywords: adolescence, violence, passiveness, appeal to the act, a refusal to acting.

* Agradecemos a Pedro Henrique Rondon pela revisão final do texto. 
$\mathrm{N}$ osso interesse, aqui, dirige-se à questão da violência psíquica, tendo como foco central a adolescência. Escolhemos nos centrar em determinadas patologias do ato, mais especialmente em situações clínicas que se caracterizam pelo negativo desse registro, ou seja, aquelas em que se observa a presença de uma recusa radical no plano do agir. Isto se manifesta, por exemplo, em uma expressiva morosidade quanto ao ingresso na vida adulta por meio de uma conduta de retraimento observada em determinados adolescentes, por exemplo. Estes parecem "resistir" ferrenhamente à superação de sua condição adolescente. Este tipo de conduta, aliada àquelas caracterizadas por um agir destrutivo, tem se mostrado bastante frequente na atualidade, incitando-nos a refletir sobre os seus fundamentos e repercussões clínicas.

Apesar de uma aparente oposição, tanto o "recurso ao ato" quanto a "recusa ao agir" se situam, no nosso entender, num mesmo campo clínico mais amplo: o das patologias do ato. Nestas, do ponto de vista do funcionamento psíquico, o ego vem apelar a uma modalidade de defesa extrema, sem mediação, que aponta, em sua base, para a insistência de uma dimensão traumática.

Como iremos mostrar, a relação entre atividade e passividade possui especial relevo dentro dessa problemática. Buscaremos explorá-la a partir de alguns vértices de análise: o caráter fronteiriço da adolescência, a questão das perdas e lutos implicados nessa travessia, a limitação dos mecanismos de defesa ao polo da ação e reação. A investigação desses elementos teóricos vem resultar na construção de uma via frutífera de compreensão desse fenômeno que estamos tratando aqui em termos de "recusa ao ato", levando-se em conta a sua relevância na adolescência atual.

\section{A ADOLESCÊNCIA COMO SITUAÇÃO FRONTEIRIÇA}

Sendo a transição da vida infantil para a vida adulta, a adolescência pode ser considerada, em si mesma, uma "situação fronteiriça”. Trata-se de uma experiência permeada pela questão dos espaços psíquicos, dos limites externos e internos. Nela vislumbramos, dentre outros aspectos, a intricada e complexa relação entre corpo e psiquismo, assim como a que se estabelece entre o eu e o outro.

Ao focalizar essa dimensão fronteiriça, inerente à adolescência, estamos atentos, ao mesmo tempo, às vertentes narcísica e alteritária dessa problemática dos limites. E a questão da origem da violência, em particular a da violência psíquica, situa-se justo aí na confluência dessas duas vertentes. "O adolescente, quando ultrapassado pela intensidade de suas próprias sensações, corre o risco de perder a capacidade de se distinguir do outro, de diferenciar o dentro e o fora. Isto se estende ao registro interno, nível da relação entre as diferentes instâncias psíquicas e das fronteiras egoicas” (CARDOSO, 2001). 
Nesse sentido, partimos do pressuposto de uma proximidade singular entre a experiência subjetiva da adolescência e aquela que permeia a dos chamados estados limites. Nestes, o problema central incide precisamente sobre a questão dos limites, em particular quanto à relação entre o eu e o outro e, de igual maneira, entre o psiquismo e o corpo. Segundo esta linha de argumentação, acrescenta-se ainda, como ponto em comum entre as duas experiências, a base traumática que ancora os estados limites, e a potencialidade traumática própria à adolescência — o que nos remete à questão dos limites da representação na vida psíquica.

O despertar pulsional que movimenta a adolescência gerando transformações psíquicas radicais nos permite pensá-la como “expressão de um lugar de conflitualização violenta, onde pulsões e defesas, investimentos narcísicos e objetais, se defrontam" (CARDOSO \& MARTY, 2008, p.10). Segundo Raymond Cahn (Apud EMMANUELLI, 2008, p.20), trata-se de um período no qual tem lugar intensa pressão pulsional: a adolescência evoca a imagem de uma "loucura das pulsões”, ou seja, uma irrupção de pulsões, tanto eróticas quanto agressivas, causa de desorganização psíquica, cuja intensidade seria diretamente proporcional à violência dessa irrupção.

Como nos estados limites, a sintomatologia adolescente pode envolver certa confusão entre o fora e o dentro e, de acordo com F. Richard (1998), a confusão entre a tentativa de se salvaguardar o narcisismo e a necessidade de reconhecimento do sujeito, da importância do olhar, da presença do outro. O conflito parece girar aqui em torno de um dos eixos mais essenciais da vida subjetiva, finda a infância: o da dependência e autonomia, um elo a mais nessa linha de continuidade que estamos traçando entre a problemática da adolescência e a dos estados limites com suas angústias, ao mesmo tempo de abandono e invasão, angústias paradoxais que nos reconduzem, de fato, àquele mesmo eixo.

Insiste ainda o mencionado autor, que a violência gerada pela irrupção da puberdade pode ser experienciada como verdadeiro traumatismo se considerarmos o quantum de angústia que pode vir a desencadear. A adolescência exige do sujeito profundo remanejamento do equilíbrio entre suas pulsões e suas defesas, em cujo pano de fundo espreita um intenso temor de passividade. Esta vivência pode impelir o ego a recorrer ao ato como tentativa extrema de escapar desse risco de permanecer submetido à intensa violência no espaço intrapsíquico, entregue a um afluxo pulsional que transgride o espaço do ego, por ultrapassar sua capacidade de trabalhar essa energia.

Mas há também os casos em que o sujeito adolescente - nesse combate travado em seu mundo interno e que se encarna nos confrontos do sujeito com obstáculos externos — - ao se ver assolado por angústia maciça de passividade, tende a se retrair, a limitar de forma significativa o seu espaço relacional com 
os objetos do mundo exterior. O sujeito faz uma espécie de retirada do campo social, numa atitude que, num plano inconsciente, parece estar a serviço de uma estranha afirmação da própria situação de passividade interna. No que concerne ao modo de funcionamento psíquico subjacente a essa situação clínica, esta “atitude" pressuporia, por parte do ego, uma espécie de antitrabalho.

Trata-se, nestes casos, de uma desistência por parte do sujeito, de um abandono de sua esfera de atividade, de sua potência à ação, de sua perspectiva de “agir no mundo”. Paradoxalmente, este recurso constitui, de certo modo, uma busca de afirmação subjetiva, como resistência radical contra a passividade ante a pulsão. Vista sob este ângulo, essa tendência à “inação” constitui uma espécie de avesso, de negativo do recurso ao ato, este recurso sendo, da mesma forma, fundamentado numa precariedade do trabalho psíquico do ego.

A recusa à ação, podendo caracterizar uma expressiva “inação”, se dá a partir de distintas manifestações, tais como o fracasso escolar, a recusa do estabelecimento de laços sociais consistentes, dentre outras condutas que terminam resultando numa morosidade importante do processo de crescimento pessoal do sujeito. Estas manifestações seriam a expressão de inércia psíquica interna que, sendo atuada, contraria violentamente o efetivo acesso à vida adulta; em suma, a superação da própria condição de adolescens: "aquele que está crescendo".

Nesse ponto identificamos uma das figuras desse fenômeno: a do prolongamento da adolescência, tão marcante, aliás, na atualidade. Analisando as especificidades do cenário da cultura contemporânea, Joel Birman (2008) pontua, dentre outras contribuições sobre o tema, as significativas transformações simbólicas ocorridas nos anos 1950 e 1960. Estas, aliadas a mudanças sociais e econômicas mais recentes, desencadeadas no final da década de 1980, tiveram, segundo ele, ressonância desestabilizadora sobre a condição adolescente - que passa a estar superposta, a partir de então, à condição de jovens adultos: “... os jovens adultos constituem uma das idades da existência mais atingidas por esse processo devastador, pois, impossibilitados de se inscreverem no mundo do trabalho e do reconhecimento simbólico de sua potência, ficam à deriva, em uma espécie de adolescência prolongada e quase infinita” (BIRMAN, 2008, p.100).

Essas modalidades destrutivas de resposta, baseadas, conforme nossa linha de argumentação, na “afirmação” de uma inércia psíquica, podem apresentar gravidade em determinados casos. Porém, por seu caráter silencioso - distinto, neste ponto, do ruidoso recurso ao ato - com frequência não é percebido como tal por aqueles com os quais esses sujeitos convivem. Esta face do problema é particularmente relevante, posto que as respostas defensivas da convocação ao ato - seja o recurso ou a recusa ao ato - não deixam de nos interrogar sobre a dimensão de apelo ao outro que, em certos casos, pode se imiscuir nessas respostas extremas. 
Porém, para que essa abertura possa de fato cumprir o seu papel, abrindo caminho à ruptura, à superação da potencialidade destrutiva dessas defesas-limite, este apelo precisaria ser acolhido pelo outro de maneira efetiva. "O pior para o adolescente, não seria, entretanto, que sua crise passasse despercebida? (....) Para fazer uma 'crise de adolescência', não é suficiente correr todos os riscos. Para que haja crise e que a crise seja um desafio, é preciso ainda que aqueles aos quais ela se endereça acusem seu recebimento” (ANDRÉ, 2009, p.32, tradução nossa).

A questão do apelo ao outro leva-nos a desbravar outra face fundamental da problemática que estamos investigando: a relação eu/outro, tendo em vista a vivência de perda, dolorosa, mas inescapável nos sujeitos adolescentes.

\section{TRABALHO DE LUTO NA ADOLESCÊNCIA}

Não se pode deixar de mencionar que rupturas traumáticas fazem parte, de modo estrutural, da adolescência. Confrontar-se com elas, na tentativa de elaborá-las, demanda do ego do sujeito adolescente árduo trabalho psíquico. Como temos acompanhado, trabalho parece representar, aliás, uma das palavras-chave na compreensão geral da adolescência, pressupondo o agenciamento de mecanismos responsáveis pelos processos de elaboração psíquica, em diferentes níveis.

De acordo com o que adiantamos em outros artigos (CARDOSO, 2001; CARDOSO \& MARTY, 2008), a exigência de efetivo trabalho psíquico diante de tantas transformações e do encontro com o "novo”, com a "diferença”, implica o rompimento com referenciais importantes da vida infantil. Este processo seria correspondente a um trabalho de luto, a ser considerado, conforme sugere Gauthier (2001) como verdadeiro "trabalho de alteridade".

Nas respostas egoicas nas quais o registro do ato é prevalente — seja através do recurso ao ato ou por meio das situações clínicas de inibição, de paralisia significativa do próprio registro do agir — a realização desse trabalho se opera de modo precário, insuficiente. Isto pode vir a impedir a efetiva superação da condição adolescente a qual, como vimos, seria potencialmente traumática e, então, não poderia ser considerada de forma dissociada do processo de violenta ruptura em relação à vida infantil que aí tem lugar.

A adolescência coloca em jogo diferentes níveis de perda cujo trabalho psíquico nem sempre se realiza de forma eficaz — consequência, dentre muitos outros fatores, de um estado de fragilidade narcísica, assim como de uma ambivalência não dialetizada no plano da relação objetal. Para se realizar o trabalho de luto, faz-se necessário o investimento em novos objetos, o que significa, em última análise, efetiva abertura à alteridade (CARDOSO, 2001). O problema da separação, da perda do objeto, se encontra no âmago da experiência da adolescência, implicando diferentes aspectos que tocam, muitos deles, na dialética do dentro 
e do fora e na intricação e articulação entre um registro mais arcaico e um registro edipiano. $\mathrm{O}$ adolescente tem que fazer o luto dos pais edipianos: precisa se separar, se destacar desses objetos que fazem parte do "passado", processo sempre custoso em razão do ruidoso retorno das fantasias infantis recalcadas que necessariamente fazem parte de sua experiência subjetiva.

A propósito do processo de luto, assinala Freud (1917/1915]/1974, p.276-277), é "fato notório que as pessoas nunca abandonam de bom grado uma posição libidinal, nem mesmo, na realidade, quando um substituto já se lhes acena”. Esta constatação pode ser estendida à própria dissolução do Complexo de Édipo e aos seus destinos na adolescência. Há nesta a exigência premente de novos investimentos com a subjacente necessidade de abdicação das figuras parentais como objeto de desejo, doravante de forma mais imperativa. Isto resulta, dentre outros aspectos, do encontro do sujeito com o seu novo corpo sexuado, da ressonância psíquica do processo de genitalização pós-pubertária.

De acordo com o que indicamos antes, o campo da relação eu/outro é solicitado de modo intenso na adolescência - como situação "fronteiriça” — assim como nos estados limites. Na adolescência, trava-se acirrada luta entre o que é da ordem da dependência dos objetos e a busca progressiva de autonomia. Mostra Chabert (1999), em suas considerações sobre os estados limites, que a falta do objeto pode ser vivenciada como o desaparecimento deste no espaço psíquico, quando a sua ausência não consegue ganhar um sentido para o sujeito que a experiencia. Nesses casos, a ausência não viria dar lugar a nenhuma construção fantasística que pudesse permitir que a dor da perda fosse associada a uma representação, abrindo, portanto, à sua elaboração.

Separar-se dos objetos parentais é vivido, então, como uma situação de perda, causa das mais importantes dos afetos depressivos em numerosos adolescentes, os quais se percebem, neste sentido, como sujeitos enlutados. “Tristes, morosos, sem vontade nem projeto, certos adolescentes parecem ser a imagem viva desse estado depressivo, devido ao inelutável da perda, que seria devida, ela mesma, ao inelutável da separação” (BERNATEAU, 2010, p.46, tradução nossa). Vemo-nos aqui diante da confusão passível de ser internamente percebida entre separação e perda, pelo risco de neutralização da linha divisória entre uma separação relativa e uma separação permanente, absoluta. Sobre este aspecto, a autora, que aborda essa faceta da adolescência em termos de uma separação com tonalidades de luto, evoca a analogia entre morte e separação, que impregnaria qualquer separação de um sentimento ou ameaça de perda. Citando Pierre Fedida (Apud BERNATEAU, 1978, p.71), ela complementa que, assim como o depressivo, o adolescente pode atuar uma "simulação da morte para se proteger da morte".

Trata-se, portanto, de uma questão de "sobrevivência" diante da ameaça de perda do outro, assim como da perda de suas próprias fronteiras egoicas. 
Para tal, as estratégias podem ser diversas, dentre elas a de se travar uma luta contra a emergência pulsional: "tentar o assassinato da pulsão para não arriscar de sucumbir a ela” (ROUSSILLON, 2010, p.195, tradução nossa). Podem aí ter lugar tanto as reações marcadas por ascetismo - pela via, por exemplo, da recusa ao ato - como aquelas em que o ego se deixa dominar pela avalanche pulsional, recorrendo de forma violenta ao ato. Nos dois casos, o dispositivo defensivo do ego é limitado, seja à ação, seja à reação, como vamos desenvolver melhor em seguida.

\section{A AÇÃO/REAÇÃO COMO "ÚLTIMA DEFESA"}

A utilização de modos primários de defesa supõe a má diferenciação entre sujeito e objeto; supõe, também, a precariedade das fronteiras egoicas em relação à alteridade interna, não dispondo o sujeito de reservas narcísicas suficientes para uma maior margem de manobra em sua relação com o objeto. Por meio do recurso ao ato, se tenta inverter o processo, transformar passividade em atividade, formando estranho "compromisso" entre o desejo radical de marcar uma diferença e a compulsão a uma aproximação extrema com o objeto. Como veremos, pela resposta de recusa radical da ação, conquanto retirada no que concerne ao encontro com o outro, se busca, da mesma forma, ainda que de maneira paradoxal, uma forma de resistência, mas supostamente ativa, no sentido quase "heroico" do termo, à ameaça de invasão de um outro interno.

Nos sujeitos adolescentes, nas situações de recurso ao ato assim como nas de recusa ao ato, há a tentativa, por parte do ego, de dominar, de "resistir" com violência à irrupção de um excesso pulsional. Ou seja, o ego parece tentar, a todo custo, dar conta da invasão em seu território por elementos irrepresentáveis: em outros termos, por marcas traumáticas que a ele foram clivadas. Um dos eixos essenciais da noção de trauma em Psicanálise diz respeito justamente à relação entre excesso pulsional e capacidade representacional, relação que traz, em sua raiz, a polaridade de atividade e passividade no âmbito da vida psíquica.

Os modelos defensivos da convocação do corpo e do ato constituem uma "última defesa”, uma “defesa de emergência”, de caráter compulsivo. Trata-se, conforme sustenta Cardoso (2002), de um modo de funcionamento psíquico situado aquém do princípio de prazer. É o princípio de des-ligação que tende a predominar nessas defesas, indicando que estariam aquém de um conflito entre a ligação e a des-ligação.

Sobre este ponto, Dominique Scarfone (1994) oferece interessante desdobramento ao propor a ideia de conflitualidade, visando distingui-la do que ele vem a denominar "paradoxalidade". Segundo ele, a possibilidade de se estabelecer um conflito psíquico já constituiria uma modalidade de ligação, processo que ele 
denomina "conflitualidade". A des-ligação, por sua vez, constituiria um registro totalmente distinto, posto que diz respeito a um princípio que vem desligar essa mesma "conflitualidade”, opondo-se, então, a qualquer forma de contenção ou de limitação do ataque pulsional. “O conflito 'não-neurótico' tem mais a ver com o paradoxo que com o conflito no sentido habitual. A paradoxalidade é aquilo que eu contrastaria com a noção de conflitualidade, assim como eu oporia esta última à livre flutuação dos processos primários no inconsciente” (SCARFONE, 1994, p.3).

Essa impossibilidade de "conflitualizar" constitui elemento essencial nas patologias graves, não neuróticas, e em particular nas patologias do ato. Nas situações clínicas em cuja base há a insistência de elementos traumáticos, são acionados no ego métodos de defesa arcaicos. Sendo assim, é o processo de tradução que se vê interrompido nesses casos. Pensar esta questão nesses termos não quer dizer, entretanto, que ante uma invasão de forças des-ligadas não haja ativação de uma defesa qualquer, mesmo que de caráter elementar. E é nessa esfera de fenômenos que o recurso ao ato e a recusa ao ato devem ser inseridos, levando-se em conta o caráter primário dessas defesas no que concerne ao registro da mentalização, do pensamento e da simbolização.

Queremos insistir no fato de os processos de elaboração psíquica — trabalho psíquico — pressuporem a realização de um trabalho de luto. Na impossibilidade de realizá-lo, a instância egoica pode apelar para esse modo de dominação, pela utilização de mecanismos defensivos precários via repetição compulsiva. Esta é limitada a um modelo mecânico e imediatista da ação e da reação, cuja lógica é atrelada, de maneira quase exclusiva, à polaridade entre atividade e passividade. Trata-se da tentativa extrema de operar uma mudança de posição, uma inversão no seu oposto. Ao não dar conta do ataque pulsional, o ego vem a repeti-lo, tentando assim reagir a ele, isto é, tentando, paradoxalmente, libertar-se de uma situação de passividade radical.

Determinados mecanismos psíquicos ilustram bem esse funcionamento de tipo paradoxal. A compulsão à repetição constitui o paradigma desse modo de funcionamento psíquico, ancorando essas defesas radicais, erigidas, em última instância, contra o risco de transbordamento pulsional. Este mecanismo primitivo, situado aquém do recalcamento, seria indicativo exato do seu fracasso. Porém, a compulsão à repetição, sem dúvida nela pressupõe, ao mesmo tempo, a presença de uma dimensão de “atividade”, mas que, de modo paradoxal, aprisiona o ego num estado de passividade, também extremada, diante do imperativo pulsional. O próprio termo compulsão nos fala de uma situação categoricamente imposta, de uma exigência interna inescapável.

Nos casos em que a compulsão à repetição se mostra dominante - e é este o cenário das respostas defensivas que apelam ao ato — não se pode, então, supor o estabelecimento de uma formação de compromisso, nem mesmo o de uma 
simples conflitualização entre diferentes sistemas. A compulsão à repetição diz respeito a respostas de autoataque, de autopunição, ainda que se possa vislumbrar na base desse sistema defensivo a tentativa de uma reação. Vale notar que o eixo ação/reação subentende uma ausência de circulação no nível do sentido, sendo o controle a sua estratégia de "enfrentamento" do traumático. Um primeiro movimento ante esse transbordamento pode ser o de tentar controlar os elementos intraduzíveis, possuindo-os, "repetindo o mal”, conforme a sugestiva expressão de Starobinski (1978). Para enfrentar a excitação permanente, uma única resposta parece ser viável: a reação.

Para Freud, o princípio de inércia, ou princípio de zero, exige do indivíduo uma ação que visa a descarga de uma energia que excede a sua capacidade de ligação. Destituído com violência, de seu "poder”, o ego é, então, compelido a agir. A imagem aqui é a da ocupação ou da possessão. É aí que identificamos de fato a presença de um paradoxo, ou melhor, de uma "paradoxalidade": não apenas o fato de o sistema egoico se ver abalado, mas o do ego retornar este ataque sobre si. Mais uma vez, tocamos aqui num dos destinos elementares da pulsão.

\section{UMA "REAÇÃO SUBJETIVA NEGATIVA"?}

O apelo a mecanismos de defesa elementares também se dá nos casos de adolescentes sobre os quais reinam a recusa à ação, a morosidade, numa resistência radical contra se tornar adulto, contra romper com a dimensão de latência que seria própria à adolescência — estado "fronteiriço" entre a vida infantil e a vida adulta. Como assinalamos acima, temos acompanhado na atualidade a tendência a um nítido prolongamento da adolescência. Em vários desses sujeitos, a resistência à mudança (com seu caráter reativo, mas afirmativo) não se faz por meio do apelo ao recurso ao ato, mas sim por significativa paralisação da sua capacidade e possibilidade de agir, de agir no mundo.

Mas, tanto o recurso a essa paralisação quanto o recurso ao ato não constituiriam, ambos, um movimento radical de reação, isto é, uma defesa atrelada ao eixo precário da ação/reação, configuração que seria própria às patologias do ato em geral? Para continuarmos a elaborar essa ideia, a noção de reação terapêtica negativa, que utilizaremos aqui numa acepção bem ampliada, vem abrir uma perspectiva interessante de análise.

Sobre o mecanismo da reação terapêutica negativa, J. B. Pontalis a ele dedica o belo artigo “Não, duas vezes não” (1988), no qual desenvolve a ideia de um princípio de agonia — de gozo e de dor - que aí estaria em ação. Neste caso, a lógica do prazer/desprazer é parcial ou totalmente recoberta por uma lógica do desespero. Visando um maior entendimento do fenômeno da reação terapêutica 
negativa, o autor explora de início o próprio termo reação, tomando-o no sentido de um re-agir, isto é, como resposta a um "agir" anterior.

A noção de reação terapêutica negativa aparece em Freud no contexto da teoria da clínica, como limite extremo colocado ao tratamento analítico. A nossa proposta neste ponto é a de acompanhar as contribuições de Pontalis no referido texto, procurando complementá-las e aplicá-las em outro contexto, no caso, aos limites do "tratamento psíquico", trabalho psíquico que constitui a própria experiência da adolescência. A questão do limite do trabalho terapêutico encontra, deste modo, uma possibilidade de desdobramento, o nosso olhar se dirigindo à questão da resistência radical que o sujeito adolescente pode oferecer ao tratamento - neste caso, ao tratamento psíquico interno que é demandado ao ego nesse profundo movimento de transformação em que passa a estar imerso.

Retomamos neste ponto a exigência de realizar um efetivo "trabalho de alteridade" e a consequente superação de um estado anterior, "familiar", rumo à aquisição de uma nova condição, vivenciada, de início, como "estrangeira”. Para ter acesso a ela, impõe-se a necessidade de novos investimentos tal um processo de luto. Tivemos a oportunidade de ressaltar antes a importância da dimensão de perda e de sua elaboração ao longo da adolescência, com implicações tanto no plano narcísico, quanto no objetal. Esta experiência de perda é referida justamente a tudo aquilo que se refere à vida infantil, situação imposta desde o mundo interno, inconsciente, ao sujeito, e imposta também pelo socius, demanda inescapável de crescer, de ter que se confrontar com o novo.

Como bem sintetiza Pontalis (1988, Op.cit.), a reação terapêutica negativa pode ser compreendida como efeito de resistência maciça ao processo de mudança. Ela se apresenta como defesa de caráter global, e mostra-se, com frequência, como intratável. Mas o autor abre um questionamento sobre essa condição, já que concebê-la desta forma significaria, no campo da clínica e do ponto de vista do analista, permanecer arraigado à mesma dominação à qual o paciente estaria, ele mesmo, submetido, em obediência, portanto, a essa mesma "lei”. As questões que a partir daí se colocam são: “... nessa defesa onde prevalece o par ação-reação, qual é a fantasia atuante? Qual é a ilusão, ou melhor, a convicção, escondida? Quais são os afetos mobilizados?" (idem, p.86).

Aprofundando a sua reflexão, o autor acrescenta que nesse tipo de resposta haveria uma necessidade compulsiva, por parte do ego, de reparar, de remediar algo. A recusa da cura implicaria, então, uma espécie de autossacrifício enquanto o sujeito não tiver "curado" os seus objetos internos. Esta tarefa se revela, entretanto, muito difícil e inesgotável, em função, dentre outros fatores, do caráter violentamente intenso e mitigado do amor e do ódio que vieram impregnar a relação de certos sujeitos com seus objetos internos. Assim, a reação terapêutica negativa sinalizaria, como diz o autor, a presença de uma "paixão” louca por 
mudar, por curar a mãe louca no interior de si. Poder reter essa "força demoníaca” no interior, poder exercê-la a partir do interior, constituiria uma tentativa de se apropriar dela e controlá-la.

A problemática do domínio, ou melhor, da “possessão” por parte do objeto interno é também ressaltada por Pontalis quando afirma que o objeto mau garante ao sujeito a sua própria permanência. Porém, o vivido de impotência do sujeito, impotência diante da iminência de perda do objeto (vivida, no caso, como perda de si) seria correlativo ao da onipotência do objeto primário. Diante disso, diante de uma excitação permanente, diante "deste excesso de mãe em si, uma única resposta: a reação" (PONTALIS, Ibid., p.88). Assim, o "não” à cura, o "não" à transformação, garante a estagnação do progresso do trabalho psíquico, posto que este é vislumbrado pelo sujeito como antecipação de uma separação insustentável, de cores catastróficas.

Nessa tentativa-limite de evitar o novo, a que esses sujeitos "negativos" se recusariam a renunciar? Mais do que representar um aprisionamento ao sofrimento, de natureza masoquista, parece se tratar de um não querer perder. Mas o sentido aqui de perder, esclarece Pontalis (1988), é duplo: não querer perder o objeto, mas não querer também ser perdedor. Junto ao "negativismo", há o desejo insistente e compulsivo de mudar o outro, de destroná-lo, se assim se pode dizer. "O sujeito faz seu aquilo que lhe escapa por natureza, ele devora o desconhecido (e se faz devorar por este)" (STAROBINSKI, 1978, p.70).

A reação terapêutica negativa pode, portanto, constituir uma forma extrema e paradoxal de se dizer não, fazendo deste não algo seu (através de um retorno sobre si), numa recusa da passividade (pela inversão em seu oposto) que representaria abdicar desse desejo de transformar o outro. Mas, insiste ainda o autor, trata-se, neste caso, de um efetivo domínio do não, implicando não uma simples inércia, uma força sofrida, mas, a partir dessa reação negativa, também exercida. Há, portanto, uma espécie de legitimidade, como ação afirmativa, na reação negativa desses sujeitos.

Pensamos que essas ideias lançam luz sobre a compreensão do fenômeno da recusa da ação na adolescência, essa tendência negativista, e, paradoxalmente, afirmada dos sujeitos que oferecem tanta resistência, a partir de distintas manifestações, a agir no mundo e a se tornar adultos, devendo abdicar, em seu próprio interior, da sua condição transitória de adolescente. A partir dessa aproximação, inspirando-nos, então, no modelo da reação terapêutica negativa, consideramos essa situação clínica como uma "reação subjetiva negativa".

Ao nos aproximarmos, na clínica, dos contornos de espaço interno desse sujeitos, nele vislumbramos, assim como naqueles que recorrem violentamente ao ato, um território ocupado pelo outro, o que em muito se diferencia da 
imagem de um deserto, conforme, mais uma vez, nos sugere Pontalis (1988), a propósito daqueles que atuam uma reação terapêutica negativa.

Mais do que protegidos, esses sujeitos parecem se manter, resistentes, exercendo uma "inação" afirmativa, uma insistente e compulsiva morosidade, resistindo à realização do trabalho de luto que seria inerente ao crescer. Porém, ao resistirem a abdicar do mesmo, à "cura” de si, ao se retraírem diante do encontro com a alteridade, com a diferença, se mantêm subjugados ao outro, numa reação subjetiva negativa. Tentativa impossível de curá-lo?

Recebido em 2/10/2010. Aprovado em 15/12/2010.

\section{REFERÊNCIAS}

ANDRÉ, J. (2009) Les 100 mots de la psychanalyse (“Crise de l’adolescence”). Paris: PUF, p.31-32.

BERNATEAU, I. (2010) L’adolescent et la séparation. Paris: PUF.

BIRMAN, J. (2008) "Adolescência sem fim: peripécias do sujeito num mundo pós-edipiano”, in CARDOSO, M.R. \& MARTY, F. (Org.) Destinos da adolescência. Rio de Janeiro: 7 Letras.

CARDOSO, M. R. (Org.) (2001) "Adolescência e violência: uma questão de fronteiras?”, in Adolescência: reflexões psicanalíticas, Rio de Janeiro: Nau /Faperj, p.41-53.

. (2002) Superego. São Paulo: Escuta.

. (Org.) (2006) Adolescentes. São Paulo: Escuta. \& MARTY, F. (2008) “Apresentação", in CARDOSO, M. \& MAR-

TY, F. (Orgs.) Destinos da adolescência. Rio de Janeiro: 7 Letras.

CHABERT, C. (1999) "Les fonctionnements limites: quelles limites?", in ANDRÉ, J. et al. Les états limites. Paris: PUF.

EMMANUELLI, M. (2008) "A clínica da adolescência”, in CARDOSO, M. \& MARTY, F. (Orgs.) Destinos da adolescência. Rio de Janeiro: 7 Letras.

FREUD, S. (1917[1915]/1974) "Luto e melancolia", in Edição Standard das Obras Psicológicas Completas de Sigmund Freud. Rio de Janeiro: Imago, p.271-291.

GAUTHIER, M. (2001) “L'énigme du deuil”. Comunicação apresentada no evento Journées Jean Laplanche, Sorrento-Itália, 12 a 14 de abril.

PONTALIS, J.-B. (1998) “Non, deux fois non”, in Perdre de vue. Paris, Gallimard.

RICHARD, F. (1988) Les troubles psychiques à l'adolescence, Paris: Dunod.

ROUSSILLON, R. (2010) “Survivre au sexuel?”, in ANDRÉ, J. \& CHABERT, C. (Orgs.) La psychanalyse de l'adolescent existe-t-elle?. Paris: PUF. 
SCARFONE, D. (1994) “Éloge de la conflictualité”, texto apresentado no Second International Conference Jean Laplanche on Psychic Conflict. Londres/Canterbury, julho.

STAROBINSKI, J. (1978) Le remède dans le mal. Nouvelle Revue de Psychanalyse, n.17.

Marta Rezende Cardoso

rezendecardoso@gmail.com 